\title{
Indirect estimation of maximal oxygen uptake for study of working populations
}

\author{
J J WELLER, F M EL-GAMAL, L PARKER, J W REED, J E COTES \\ From the Respiration and Exercise Laboratory, University Departments of Occupational Health and \\ Physiological Sciences, Newcastle upon Tyne, UK
}

\begin{abstract}
A total of 345 shipyard workers (aged 23 to 47) volunteered to perform progressive exercise on a cycle ergometer (15 W/min increments) up to the symptom limited maximum. The results were used to obtain maximal oxygen uptake $\left(\mathrm{n}_{2} \max \right)$, the oxygen uptake at a respiratory exchange ratio of unity $\left(\mathrm{nO}_{2}\right.$ at $\left.\mathrm{R}_{1.0}\right)$, and cardiac frequency at an oxygen uptake of $45 \mathrm{mmol} / \mathrm{min}$ $\left(\mathrm{fC}_{45}\right)$. In this group 156 men $\left(45 \%\right.$ of initial population) attained $\mathrm{nO}_{2}$ max as defined, $108(31 \%)$ withdrew or did not exercise maximally, and $49(14 \%)$ had transient electrocardiographic abnormalities. For the 156 men extrapolation of the relation of cardiac frequency on oxygen uptake to the predicted maximal cardiac frequency resulted in overestimation of $\mathrm{nO}_{2} \max$ by $9 \cdot 6 \%$. $\mathrm{n}_{2} \mathrm{Max}$ per $\mathrm{kg}$ body mass was negatively correlated with body mass. $\dot{\mathrm{nO}}_{2} \mathrm{Max}$ (mean value $130.6 \mathrm{mmol} / \mathrm{min}$ ) was described in terms of age, fat free mass, smoking (yes or no), and level of habitual activity (rated 1 to 4): the standard error of the estimate (SEE) was $17.3 \mathrm{mmol} / \mathrm{min}\left(\mathrm{R}^{2} 0.42\right)$; the equation was suitable for reference values. For estimating the $\mathrm{n}_{2}$ max of individual men an empirical relation based on $\dot{n}_{2}$ at $\mathrm{R}_{1.0}, \mathrm{fC}_{45}$, fat free mass, and \% body fat had an SEE of $12 \cdot 1 \mathrm{mmol} / \mathrm{min}\left(\mathrm{R}^{2} 0.67\right)$. Seventy six per cent of men ( $88 \%$ of those who exercised) attained $\mathrm{nO}_{2}$ at $\mathrm{R}_{1.0}$ (oxygen uptake approximately $73 \%$ of maximum). Thus the $\dot{n}_{2}$ max could be estimated in a higher proportion of men than could achieve $\mathrm{nO}_{2}$ max. The estimate is appropriate for assessing exercise capacity in relation to employment. For investigating the determinants of exercise capacity in groups of subjects the submaximal index, $\mathrm{nO}_{2}$ at $\mathbf{R}_{1 \cdot 0}$, is more informative.
\end{abstract}

Maximal oxygen uptake $\left(\dot{\mathrm{n}}_{2} \max \right)$ reflects the power output for work of 4-10 minutes duration; a high value is a selection criterion for some tasks and in a population is evidence for high customary activity and hence physical fitness. It is measured during progressive exercise up to the point when oxygen uptake reaches a plateau. ${ }^{1}$ An alternative end point is when cardiac frequency attains the predicted maximum ${ }^{2}$; this presupposes that the reference value for maximal cardiac frequency applies to the study population but it may not. The measurement procedure requires a high level of motivation, causes distress to some subjects, entails medical and electrocardiographic surveillance, and occasionally precipitates myocardial ischaemia or cardiac arrest. ${ }^{3}$ Indirect estimation of $\mathrm{nO}_{2}$ max appears preferable; however, the method should be reproducible and the result equivalent to

Accepted 3 August 1987 that obtained by direct measurement. The $\mathrm{nO}_{2} \max$ is usually predicted by extrapolating the relation of cardiac frequency on oxygen uptake for progressive submaximal exercise up to the predicted maximal cardiac frequency, but the accuracy of prediction is poor. ${ }^{2}$ Greater accuracy is achieved using blood lactic acid concentration ${ }^{46}$; however, the requisite blood sampling is not always practicable. In a pilot study prediction from submaximal exercise, cardiac frequency, fat free mass, and vital capacity showed promise, ${ }^{7}$ but it was less satisfactory when applied to another population. ${ }^{8}$ After the lead given by Issekutz and other workers, ${ }^{9-11}$ we explored predicting $\dot{n} \mathrm{O}_{2}$ max from oxygen uptake at a respiratory exchange ratio of unity. ${ }^{12}$ The present paper applies the method to shipyard workers; the relation contains appropriate components and the estimated $\mathrm{nO}_{2} \max$ is related to activity and age in a manner consistent with other studies. The method provides an accurate way of estimating $\mathrm{n}_{2}$ max from the results of a submaximal exercise test in working populations. 


\section{Methods}

The subjects were 345 shipyard workers (welders, caulker burners, and other tradesmen) aged 23-47 who volunteered for the study which was approved by the local ethical committee. The study arose from an investigation into the long term effects of fumes from welding and caulker burning. To this end the subject underwent an assessment of lung function, the Medical Research Council Questionnaire on Respiratory Symptoms was completed, and additional questions asked about chest pain and habitual activity: the latter were used to rate activity outside working hours on a four point scale (table 1). The questionnaire was used to identify men with wheeze or chronic bronchitis and smokers or ex-smokers. Fat free mass and body fat as a percentage of body mass were estimated by the method of Durnin and Womersley ${ }^{13}$ from body mass and skinfold thickness measured with Harpenden skin calipers (Holtain). Details are given elsewhere. ${ }^{14}$

Exercise was preceded by measuring blood pressure and 12 lead electrocardiography (ECG). This information and the questionnaire were used to screen out subjects for whom the test was inappropriate. The exercise was performed on a Siemens ergomed cycle ergometer at a pedal frequency of 60 a minute. The ECG lead $\mathrm{CM} 5^{15}$ was recorded and scrutinised during the test. A mouthpiece and low resistance valve box of deadspace 0.051 were used. Ventilation minute volume was recorded using a rotating vane anemometer with microprocessor output (Morgan); this was calibrated before each period of exercise using a procedure which was itself checked by an independent method. The back pressure to ventilation was less than $2 \mathrm{~mm} \mathrm{H}_{2} \mathrm{O}$ at a flow rate of $851 / \mathrm{min}$. Mixed expired gas was sampled for analysis using a Morgan paramagnetic meter for oxygen and infrared analyser for carbon dioxide; the analysers' calibrations were checked before each session. A microcomputer and printer (Morgan) displayed the raw measurements together with oxygen uptake, carbon dioxide output, and respiratory exchange ratio each half minute during exercise. Subsequently graphs were printed relating the ventilation, cardiac frequency, and respiratory exchange ratio to oxygen uptake and the tidal volume to ventilation.

Table 1 Score for habitual activity outside working hours

\begin{tabular}{llll}
\hline Score & $\begin{array}{l}\text { Strenuous activities } \\
\text { a week }\end{array}$ & $\begin{array}{l}\text { Cycling to work } \\
\text { (miles) }\end{array}$ & Comment \\
\hline 1 & None & 0 & Sedentary \\
2 & $1-2$ & $<2$ & Some activity \\
3 & $3-4$ & $2-5$ & Above average \\
4 & $>4$ & $>5$ & Very active \\
\hline *Competitive sports; other activities as appropriate.
\end{tabular}

*Competitive sports; other activities as appropriate.
The intermediate results were used (i) for quality control during exercise, (ii) to determine if exercise should be stopped prematurely, and (iii) for deriving by interpolation the ventilation and cardiac frequency at an oxygen uptake of $45 \mathrm{mmol} / \mathrm{min}\left(1.01 / \mathrm{min}, \dot{\mathrm{V}}_{\mathrm{E}} 45\right.$, $\mathrm{fC}_{45}$ respectively) and the oxygen uptake at a respiratory exchange ratio of unity $\left(\mathrm{n}_{2}\right.$ at $\left.\mathrm{R}_{1 \cdot 0}\right)$. Interpolation was performed by the least squares method over the range where the data appeared linear. The anaerobic threshold was obtained by inspection of the relation of ventilation on uptake of oxygen. ${ }^{8}$

The subject rested on the ergometer for two minutes, pedalled at zero load for one minute, and then worked with increasing intensity ( $15 \mathrm{~W}$ increments) until respiratory exchange ratio just exceeded unity. After a 20 minute rest the exercise was restarted at a rate $20 \mathrm{~W}$ below that previously attained; the increments were $20 \mathrm{~W}$ a minute up to the maximum the subject was prepared to tolerate. Exercise was terminated by the operator in the event of systolic hypertension $(200 \mathrm{~mm} \mathrm{Hg})$ or electrocardiographic abnormality (ST depression $>2 \mathrm{~mm}$, three consecutive ventricular ectopic beats or seven such beats in one minute) or when the subject could go no further. The highest recorded oxygen uptake was accepted as maximal if it differed from that for the previous minute by less than $4 \mathrm{mmol} / \mathrm{min}$ or the maximal cardiac frequency was not less than $10 / \mathrm{min}$ below the reference value or both. ${ }^{2}$ The reference value was also used as an endpoint in the prediction of $\mathrm{nO}_{2}$ max by extrapolation of the relation of cardiac frequency on oxygen uptake obtained during the first period of exercise up to $R_{1 \cdot 0}$.

Results were analysed using an IBM 370 computer and the Statistical Package for the Social Sciences of the University of Michigan. ${ }^{16}$ The methods included Student's paired $t$ test and linear multiple regression analysis. For the latter the variables were added one at a time, starting with that which most reduced the variance. The precision of the estimation of the dependent variable was expressed in terms of its standard error (SEE) or as the goodness of fit of the regression equation, in terms of $\mathbf{R}^{2}$, the proportion of variation explained by the independent variables. The $5 \%$ level of probability was accepted as significant.

\section{Results}

DESCRIPTION OF SUBJECTS

Questionnaires, lung function tests, and anthropometry were applied to $345 \mathrm{men}$. Of these, 45 then declined exercise and four were considered to be unsuitable on account of hypertension (diastolic pressure $>110 \mathrm{~mm} \mathrm{Hg}$ ) or previous myocardial infarction. A total of 296 men performed the progressive exercise test; 261 completed it by attaining $R_{1 \cdot 0}, 25$ gave 
Table 2 Subject participation in the progressive and maximal exercise tests

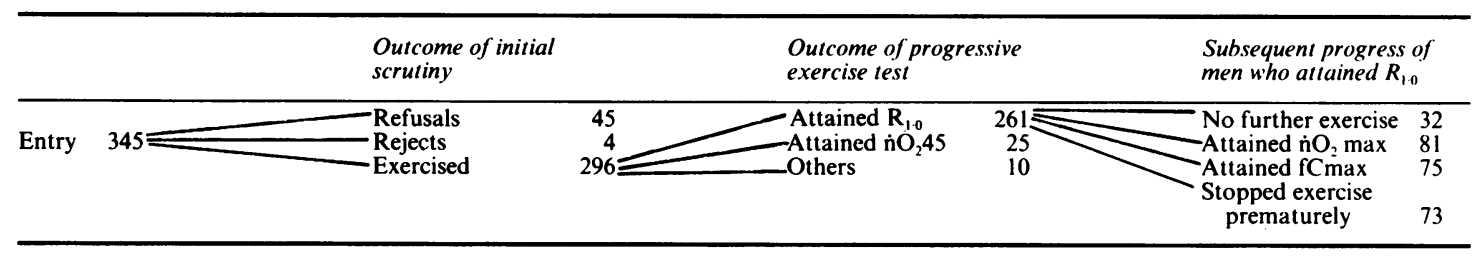

up or developed ECG changes before this endpoint but reached an oxygen uptake of $45 \mathrm{mmol} / \mathrm{min}$, and the 10 other men provided no usable information. Of the men who attained $R_{1.0}, 32$ were stopped at this point, 81 attained a plateau of oxygen uptake, 75 achieved their maximal cardiac frequency as defined, and 73 gave up before this endpoint was reached (table $2)$. In total, 52 men did not attempt one or other exercise test, 56 exerted insufficient effort, six had skeletal problems, 49 had ECG abnormalities at rest or on exercise, two suffered from hypertension, and in 24 only incomplete information was obtained. Mean results by age group for the subjects who attained $R_{1.0}$ are given in table 3 .

\section{RESULTS FOR MAXIMAL EXERCISE}

The mean ${ }^{n} \mathrm{O}_{2}$ max for the 81 men who achieved a plateau of oxygen uptake was $127.4 \mathrm{mmol} / \mathrm{min}$; this was significantly less than that predicted by the extrapolation method. The maximal cardiac frequency (fC max) was also lower than predicted (table 4). For these men $\dot{n}_{2}$ max was described by a multiple regression on $\dot{\mathrm{nO}}_{2}$ at $\mathrm{R}_{1.0}$, forced vital capacity, $\mathrm{fC}_{45}$, age, fat free mass, stature, the occurrence of regular wheeze, and a history of previous pneumonia (the latter tivo scored as present or absent) (SEE 10.4 $\mathrm{mmol} / \mathrm{min}, R^{2} 0.76$ ). The equation was used to estimate $\mathrm{nO}_{2} \max$ in the 75 men who attained a maximal cardiac frequency (defined) but not a plateau of oxygen uptake. For these subjects the maximal cardiac frequencies were similar to those in the other group (table 4) and the observed $\mathrm{nO}_{2} \max$ $(134.9 \mathrm{mmol} / \mathrm{min})$ did not differ significantly from the estimate $(133.8 \mathrm{mmol} / \mathrm{min})$. The results for the two groups of men were pooled for the definitive analysis.

\section{DESCRIPTION OF $\mathrm{nO}_{2}$ MAX IN TERMS OF OTHER \\ VARIABLES}

$\dot{\mathrm{n}} \mathrm{O}_{2}$ Max was described by a multiple regression equation with age, fat free mass, activity score, and current smoking as the independent variables (SEE $17.3 \mathrm{mmol} / \mathrm{min}, \mathrm{R}^{2} 0 \cdot 42$ ). When prediction was based on oxygen uptake at a respiratory exchange ratio of unity, the SEE was $14 \cdot 1 \mathrm{mmol} / \mathrm{min}$. It was reduced to $12.1 \mathrm{mmol} / \mathrm{min}\left(\mathrm{R}^{2} 0.67\right)$ by also including in the equation fat free mass and either \% fat or forced vital

Table 3 Mean results by age groups

\begin{tabular}{|c|c|c|c|c|}
\hline & \multicolumn{4}{|c|}{ Age groups (years)* } \\
\hline & $25-29$ & $30-34$ & $35-39$ & $40-47$ \\
\hline No (but see table 2) & 76 & 54 & 50 & 80 \\
\hline Age (yr) & $27 \cdot 0$ & $31 \cdot 8$ & $37 \cdot 2$ & $43 \cdot 1$ \\
\hline Stature $(\mathrm{m})$ & 1.73 & 1.75 & 1.74 & 1.73 \\
\hline Body mass (BM) (kg) & $73 \cdot 5$ & 78.9 & $77 \cdot 5$ & 77.4 \\
\hline Fat $(\%)$ & $16 \cdot 3$ & 19.9 & $20 \cdot 4$ & $22 \cdot 4$ \\
\hline Fat free mass $(\mathrm{FFM})(\mathrm{kg})$ & $61 \cdot 3$ & $62 \cdot 7$ & $61 \cdot 5$ & $59 \cdot 3$ \\
\hline Activity score & 1.85 & 1.60 & 1.56 & 1.45 \\
\hline \multicolumn{5}{|l|}{ Lung function: } \\
\hline Forced expiratory volume $\left(\mathrm{FEV}_{1}\right)(1)$ & $4 \cdot 10$ & $4 \cdot 13$ & 3.93 & 3.57 \\
\hline Forced vital capacity (FVC) (1) & $5 \cdot 30$ & $5 \cdot 38$ & $5 \cdot 25$ & 4.93 \\
\hline \multicolumn{5}{|l|}{ Submaximal exercise: } \\
\hline Ventilation $\left(\mathrm{V}_{\mathrm{E}} 45\right)(1 / \mathrm{min})$ & $22 \cdot 7$ & $23 \cdot 0$ & $23 \cdot 3$ & $24 \cdot 2$ \\
\hline Cardiac frequency $\left(\mathrm{fC}_{45}\right)(\min 1)$ & $104 \cdot 6$ & $105 \cdot 3$ & $106 \cdot 1$ & $108 \cdot 5$ \\
\hline Tidal volume $\left(\mathrm{Vt}_{30}\right)(1)$ & 1.62 & 1.64 & 1.73 & 1.59 \\
\hline $\mathrm{nO}_{2}$ at anaerobic threshold $(\mathrm{mmol} / \mathrm{min})$ & $79 \cdot 4$ & 76.0 & $73 \cdot 6$ & 71.2 \\
\hline$\dot{\mathrm{n}} \mathrm{O}_{2}$ at $\mathrm{R}_{1 \cdot 0}(\mathrm{mmol} / \mathrm{min})$ & $98 \cdot 4$ & $96 \cdot 1$ & $95 \cdot 4$ & $86 \cdot 8$ \\
\hline \multicolumn{5}{|l|}{ Maximal exercise: } \\
\hline $\mathrm{nO}_{2} \max ($ direct or estimated) $(\mathrm{mmol} / \mathrm{min})$ & $131 \cdot 2$ & $124 \cdot 8$ & $127 \cdot 1$ & $117 \cdot 5$ \\
\hline $\mathrm{nO}_{2} \max (\mathrm{St}, \mathrm{BM})(\mathrm{mmol} / \mathrm{min})$ & 140.6 & $137 \cdot 4$ & 121.6 & 118.9 \\
\hline $\mathrm{nO}_{2} \max (\mathrm{St}, \mathrm{FFM})(\mathrm{mmol} / \mathrm{min})$ & 138.9 & $140 \cdot 9$ & 121.6 & $119 \cdot 2$ \\
\hline $\mathrm{n} \mathrm{O}_{2} \max (\mathrm{St}, \mathrm{BM}) / \mathrm{BM}(\mathrm{mmol} / \mathrm{min} / \mathrm{kg})$ & 1.92 & 1.74 & 1.56 & 1.52 \\
\hline $\mathrm{nO}_{2} \max (\mathrm{St}, \mathrm{FFM}) / \mathrm{FFM}(\mathrm{mmol} / \mathrm{min} / \mathrm{kg})$ & $2 \cdot 28$ & $2 \cdot 23$ & 1.96 & 2.01 \\
\hline
\end{tabular}

${ }^{*}$ One subject was aged 23 so his results do not appear in the table.

St, standardised to mean BM or FFM using equations 1 and 2 in text. 
Table 4 Observed and predicted $f C$ max, observed $\dot{n} \mathrm{O}_{2}$ max, and $\dot{n} \mathrm{O}_{2}$ max predicted by extrapolation for subjects who attained a plateau of oxygen uptake during the maximal exercise test $(n=81)$

\begin{tabular}{|c|c|c|c|}
\hline & Mean & $S D$ & Range \\
\hline \multicolumn{4}{|l|}{ fC Max $(\min 1): *$} \\
\hline Observed & $182.0+$ & $8 \cdot 38$ & 163-202 \\
\hline & $187 \cdot 7$ & $4 \cdot 10$ & $180-193$ \\
\hline Observed & $127 \cdot 4+$ & $20 \cdot 6$ & $88-184$ \\
\hline Extrapolated & $139 \cdot 8$ & $30 \cdot 6$ & $84-260$ \\
\hline
\end{tabular}

*The corresponding mean values for 75 subjects who met the cardiac frequency criterion for $\dot{n O}_{2}$ max were 181 and 188 a minute.

†Significantly different from predicted $\mathrm{p}<0.05$.

capacity (table 5). Adding forced expiratory volume, current smoking, whether or not the subject had discontinued smoking, and age slightly but significantly improved the description. $\mathrm{nO}_{2}$ Max was significantly correlated with body mass and fat free mass; the linear relations were:

$$
\begin{gathered}
\dot{\mathrm{nO}}_{2} \max =\begin{array}{c}
0.58 \text { body mass }(\mathrm{kg})+88.9(\mathrm{SEE} 21.7) \\
\mathrm{mmol} / \mathrm{min}(\text { equation } 1)
\end{array} \\
\dot{\mathrm{nO}}_{2} \max =\begin{array}{c}
1.56 \mathrm{fat} \text { free mass }(\mathrm{kg})+34.9(\mathrm{SEE} 20.0) \\
\mathrm{mmol} / \mathrm{min}(\text { equation } 2)
\end{array}
\end{gathered}
$$

The proportionalities $\dot{\mathrm{n}}_{2}$ max/body mass and $\dot{\mathrm{nO}}_{2} /$ FFM were negatively correlated with body mass. $\dot{\mathrm{n}}_{2} \mathrm{Max}$ could also be described with similar precision in terms of body mass to the power of $0 \cdot 31$.

\section{DESCRIPTION OF INDICES OBTAINED DURING SUBMAXIMAL EXERCISE}

Oxygen uptake at a respiratory exchange ratio of unity $\left(\dot{\mathrm{nO}}{ }_{2}\right.$ at $\mathrm{R}_{1.0}$, mean value $\left.93.8 \mathrm{mmol} / \mathrm{min}\right)$ was correlated with anaerobic threshold (mean value $75 \cdot 1$ $\mathrm{mmol} / \mathrm{min}, \mathrm{r}=0.70$ ). It was related to activity score, smoking, and fat free mass. After allowing for these variables ex-smokers with a history of wheeze had a below average $\dot{n O}_{2}$ at $\mathrm{R}_{1.0}$ and men with chronic bronchitis an above average value. Cardiac frequency at an oxygen uptake of $45 \mathrm{mmol} / \mathrm{min}\left(\mathrm{fC}_{45}\right)$ was negatively correlated with the activity score, fat free mass, and forced vital capacity; it was higher by nine beats a minute in subjects who gave a history of pleurisy compared with those who did not. The respiratory exchange ratio at an oxygen uptake of 45 $\mathrm{mmol} / \mathrm{min}$ was positively correlated with exercise ventilation $\left(\dot{\mathrm{V}}_{\mathrm{E}} 45\right.$ and $\left.\mathrm{Vt}_{30}\right)$ and with $\mathrm{fC}_{45}$ standardised for fat free mass: it was higher in men who worked as caulker burners compared with other occupational groups.

\section{Discussion}

MAXIMAL OXYGEN UPTAKE

Information on exercise capacity is used as a guide to suitability for heavy work, particularly at preemployment examination, after illness or injury, and when the work is performed infrequently; the relevant occupations include professional sport, membership of rescue and fire brigades, the armed forces, police, deep sea divers, and occupations entailing heavy work. The exercise capacity is also used to assess the physical fitness of occupational and other populations and hence the possible need for changes in lifestyle or recreational facilities. For persons who are fit and highly motivated the maximal oxygen uptake, which is a measure of exercise capacity, can usually be measured without difficulty. In other circumstances the direct measurement is frequently unacceptable. It is also inefficient since in the present instance, despite some initial selection, there was a high dropout rate from both medical and psychological causes (respectively $16 \%$ and $31 \%$ ); these aspects are considered below. The maximal exercise test starts with submaximal exercise, however, and the submaximal results may be used to estimate the exercise capacity instead of or before making the direct measurement.

ESTIMATION OF MAXIMAL OXYGEN UPTAKE: USE OF $\dot{n} \mathrm{O}_{2}$ MAX AT $\mathrm{R}_{1.0}$

The widely used extrapolation procedure for predicting $\mathrm{nO}_{2}$ max from cardiac frequency is unreliable because both the relation between cardiac frequency and oxygen uptake is not rectilinear ${ }^{17}$ and the Scandinavian reference values for maximal cardiac frequency do not apply to all subjects. In the present instance they overestimated the measured $\mathrm{fC}$ max by $2.7 \%$ (table 4). Rectilinear extrapolation to the predicted maximal cardiac frequency overestimated the measured $\mathrm{nO}_{2}$ max by $9 \cdot 6 \%$, indicating that the shape of the $\dot{\mathrm{nO}}_{2} / \mathrm{fC}$ relation also contributed to the discrepancy.

Estimation based on cardiac frequency at a single oxygen uptake was previously found to be unsatisfactory for predicting $\mathrm{nO}_{2}$ max though it could be used to

\begin{tabular}{|c|c|}
\hline Without exercise & $B$ Including exercise \\
\hline $\begin{array}{l}\text { Coefficient terms: } \\
1.43 \text { FFM (kg) } \\
-0.95 \text { Age (yr) } \\
6.31 \text { Activity }(1-4) \\
-8.06 \mathrm{Sm}(\mathrm{yes} / \mathrm{no}) \\
\text { Constant } 69.5 \\
\text { SEE } 17.3(\mathrm{mmol} / \mathrm{min}) \\
\mathrm{R}^{2}+0.42\end{array}$ & $\begin{array}{l}0.626 \mathrm{nO}_{2} \text { at } \mathrm{R}_{1 \cdot 0}(\mathrm{mmol} / \\
\mathrm{min})^{*} \\
0.78 \mathrm{FFM}(\mathrm{kg}) \\
-0.86 \mathrm{Fat}(\%) \\
-0.29 \mathrm{fC} 45\left(\mathrm{~min}{ }^{1}\right) \\
70 \cdot 1 \\
12.1(\mathrm{mmol} / \mathrm{min}) \\
0.67\end{array}$ \\
\hline
\end{tabular}
predict the Harvard pack index. ${ }^{18}$ Prediction of

Table 5 Linear regression equations for estimating $\dot{n} \mathrm{O}_{2}$ max $(n=156, \bar{x}=130 \cdot 6, \mathrm{mmol} / \mathrm{min})$

*Without other variables $\dot{\mathrm{nO}}_{2} \max =0.78 \dot{\mathrm{nO}}_{2}$ at $\mathrm{R}_{10}+54.8(\mathrm{SEE}$ 14.1, $\mathrm{R}^{2} 0 \cdot 61$ )

†Proportion of variance explained by regression. 
$\mathrm{nO}_{2}$ max was improved by including fat free mass and forced vital capacity in the prediction equation. ${ }^{7}$ Substitution of stroke volume for fat free mass and $\mathrm{fC}_{45}$ further improved the accuracy of prediction ${ }^{8}$ but the measurement entailed rebreathing which was disagreeable and difficult for some subjects. The alternative use of anaerobic threshold, estimated indirectly from the relation of ventilation on oxygen uptake, did not have this disadvantage but the estimation procedure was subject to observer error. ${ }^{19}$ Use of the oxygen uptake at a respiratory exchange ratio of unity has the advantages of being at least as good a predictor of $\dot{n O}_{2}$ max as the other variables, of being readily estimated, and having an acceptable reproducibility -in one instance $5 \%{ }^{8}$ Because it was correlated with anaerobic threshold, $\mathrm{nO}_{2}$ at $\mathrm{R}_{1.0}$ also provided an estimate of capacity for prolonged work. In the present study the index was obtained on $76 \%$ of the initial population which represented $88 \%$ of the men who were prepared to exercise. Both the proportion in this category and the number who persevered to attain $R_{1.0}$ would have been increased if the men had had a material interest in the result. In addition, of those who were stopped on account of electrocardiographic abnormality, the great majority performed successfully when the test was repeated a few weeks later. This suggested that the immediate cause was apprehension and was reversible. The number of such abnormalities and the proportion which resulted from ischaemic heart disease increased with age ${ }^{20}$ but over the present age range the test up to $R_{1.0}$ appeared to strike the right balance between, on the one hand, adequate intensity of effort and, on the other, safety, acceptability, and technical complexity. The precision of prediction (SEE approximately $12 \mathrm{mmol} / \mathrm{min}$ depending on which variables were included) was not bettered by any of the alternatives that have been tried to date.

INTER PRETATION OF $\dot{\mathrm{nO}}{ }_{2}$ MAX

$\dot{\mathrm{nO}}_{2} \mathrm{Max}$ is interpreted with respect to the reference value, the energy requirements of the occupation, ${ }^{21}$ and the cause of any limitation on medical grounds. The reference value may be the previous result for the particular subject or the average result for a person having similar attributes. The reference variables should then be available without recourse to exercise. Arising from the present study the best combination was age, fat free mass, activity category, and smoking (table 5, equation A). The partial regression coefficients on age and activity category were similar to those found by Jones et al $^{22}$ and the overall results were also similar. The inclusion of smoking, however, seemed to the present authors to be appropriate. In addition, fat free mass was a more relevant reference variable than stature and body mass used by the
Canadian workers since body mass included body fat which did not contribute to exercise capacity. Body mass was also correlated with stature, hence the reference variables were not independent and this could have reduced the validity of the reference equation. The variability about the present equation $\left(R^{2} 0.42\right)$ was similar to that for most indices of lung function $\left(R^{2} \simeq 0.4-0.5\right)$ so like them should have a wide range of applications.

For purposes of comparison between subjects the $\dot{\mathrm{nO}}_{2}$ max is usually expressed per unit of body mass or fat free mass. For the present subjects, however, $\mathrm{nO}_{2}$ $\max / \mathrm{kg}$ was negatively correlated with mass. This was due to the relation between the variables not being a proportionality but a linear regression with a significant constant term. On this account $\dot{n} \mathrm{O}_{2} \mathrm{max} / \mathrm{kg}$ was not a valid index ${ }^{23}$ 24; the $\dot{\mathrm{nO}}_{2}$ at a standard mass could be used (table 3 ) or the $\dot{\mathrm{nO}}_{2}$ max expressed per unit of body muscle - for example, thigh muscle width or total body potassium, both of which bear a proportional relation to $\mathrm{nO}_{2}$ max. $^{?}$

The estimated $\dot{n O}_{2}$ max provides an index of physical condition in subjects capable of exercising up to a respiratory exchange ratio of unity. It also indicates what the exercise capacity would be, given favourable circumstances. Nevertheless, the aerobic capacity could still be limited by medical conditions; the commonest condition is ischaemic heart disease which is commonly looked for by stress electrocardiography at a workload equivalent to $80 \%$ of $\dot{n O}_{2}$ max. This work rate is not much greater than that needed to attain $\mathrm{R}_{1 \cdot 0}$ (on average $73 \%$ of $\mathrm{nO}_{2} \max$ ) so the two procedures could readily be combined.

The nO $_{2}$ max estimated from submaximal data is likely to be most useful in relation to employment. It might also be used to investigate factors that underlie exercise capacity other than those which contribute to the estimate. For this application the number of reference variables should be minimal, hence forced expiratory volume, age, smoking history, and score for habitual activity were omitted from the equation despite their contributing significantly to the description of $\mathrm{nO}_{2}$ max. In addition, in order to validate the use of estimated $\dot{\mathrm{nO}}_{2} \max$ the analysis was also performed using the measured $\dot{\mathrm{nO}}_{2}$ max as a dependent variable. The contributions of habitual activity and age were rated equally by both methods. Current smoking was identified as reducing the measured $\dot{\mathrm{nO}}_{2} \max$ by on average $6 \%$. It did not apparently contribute to estimated $\mathrm{nO}_{2}$ max but reduced by $8.6 \%$ the $\mathrm{nO}_{2}$ at $\mathrm{R}_{1.0}$ which was one of the constituents of the prediction equation. Adverse effects of previous pleurisy and of respiratory symptoms sufficient for the subject to abandon smoking were also identified in the component terms but not in the $\mathrm{nO}_{2}$ max estimated from them. Thus for assessing the physiological 


\section{Estimation of maximal oxygen uptake}

determinants of physical fitness the $\mathrm{nO}_{2}$ at $\mathbf{R}_{1 \cdot 0}$ and other component terms in the equation were informative in their own right and could be used as indices in population studies. The n $\mathrm{O}_{2}$ at $\mathrm{R}_{1.0}$ should probably not be used in relation to claims for compension since, if the subject hyperventilated, an artificially low value might be obtained. But with hyperventilation the directly measured $\mathrm{nO}_{2}$ max would not be reliable either. ${ }^{25}$

In conclusion reference values for $\dot{n O}_{2} \max$ in working men have been obtained. The estimation of $\mathrm{nO}_{2}$ max from the results of a submaximal exercise test and related variables has been shown to be valid for shipyard workers aged 23 to 47 . The test is safer, less stressful, more acceptable, and completed by a higher proportion of subjects than direct measurement and has a place in assessing work capacity in relation to occupation. For comparison between individuals of different size the results should be expressed at a standard body mass or fat free mass and not per $\mathrm{kg}$. Factors that contribute to $\dot{\mathrm{nO}}_{2} \max$ may be investigated through their effects on the components of the prediction equation. Estimated $\mathrm{nO}_{2}$ max may be misleading in the presence of disease processes or psychological conditions which affect the capacity for exercise. Its use in population studies has still to be evaluated.

This paper arose from a study into the health of welders and caulker burners at Swan Hunter Shipbuilders and we are greatly indebted to all who contributed to the arrangements, including Dr J F Wollaston, S R N P O'Malley, Mr J Cowan, and Mr B Cockcroft. Dr D J Chinn and Miss NG Bridges completed questionnaires of symptoms and Dr R J C Hall and Dr C P Ashby helped with the electrocardiographic surveillance. Dr E J Bassey kindly commented on the manuscript. The Medical Research Council provided financial support to JEC and JJW. Dr F M El-Gamal and Mrs L Parker were respectively supported by grants from the Committee of University Vice-Chancellors and the Luccock Research Studentship of the University of Newcastle upon Tyne.

\section{References}

1 Taylor HL, Buskirk E, Henschel A. Maximal oxygen uptake as objective measure of cardio-respiratory performance. $J \mathrm{Appl}$ Physiol 1955;8:73-80.

2 Åstrand PO, Rodahl K. Textbook of work physiology. 3rd ed. London: McGraw-Hill, 1986:354-90.

3 Siscovick DS, Weiss NS, Fletcher RK, Lasky T. The incidence of primary cardiac arrest during vigorous exercise. $N$ Engl $J$ Med 1984;311:874-7.
4 Ivy JL, Withers RT, Van Handel PJ, Elger DH, Costill DL. Muscle respiratory capacity and fibre type as determinants of the lactate threshold. J Appl Physiol 1980;48:523-8.

5 Mortimer IL, Reed JW. Prediction of maximal oxygen uptake from submaximal blood lactate concentration. $J$ Physiol 1982;328:73P.

6 Tanaka K, Matsuura Y. Marathon performance, anaerobic threshold and onset of blood lactate accumulation. J Appl Physiol 1984;57:640-3.

7 Cotes JE, Davies CTM, Edholm OG, Healy MJR, Tanner JM. Factors relating to the aerobic capacity of $\mathbf{4 6}$ healthy British males and females, ages 18 to 28 years. Proc R Soc Lond (Biol) 1969:174:91-114.

8 Mortimore IL. The aerobic capacity of healthy people. Newcastle upon Tyne: University of Newcastle upon Tyne, 1982. (PhD thesis.)

9 Issekutz B Jr, Birkhead NC, Rodahl K. Use of respiratory quotient in assessment of aerobic work capacity. J Appl Physiol 1962;17:47-50.

10 Shephard RJ. Respiratory gas exchange ratio and prediction of aerobic power. J Appl Physiol 1975;38:402-6.

11 Wasserman K, Whipp BJ, Koyal SN, Beaver WL. Anaerobic threshold and respiratory gas exchange during exercise. $J$ Appl Physiol 1973;35:236-43.

12 Mortimore IL, Reed JW. The effect of diet on the respiratory exchange ratio and aerobic capacity in man. $J$ Physiol 1982;330:59-60P.

13 Durnin JVGA, Womersley J. Body fat assessed from total body density and its estimation from skinfold thickness: measurements on 481 men and women aged $16-72$ years. $B r J$ Nutr 1974:32:77-97.

14 Cotes JE. Lung function: assessment and application in medicine. 4th ed. Oxford: Blackwell Scientific Publications, 1979.

15 Blackburn H, Taylor HL, Okamoto N, Rautaharj P, Mitchell PL, Kirkhof AC. Standardisation of the exercise electrocardiogram. A systematic comparison of chest lead configurations employed for monitoring during exercise. In: Karvonen MJ, Barry AJ, eds. Physical activity and the heart. Springfield, Ill: Thomas, 1967:101-33.

16 Nie NH, Hull CH, Jenkins JC, Steinbrenner K, Bent DH. Statistical package for the social sciences. 2nd ed. New York: McGraw-Hill, 1975.

17 Maritz JS, Morrison JF, Peter J, Strydom NB, Wyndham CH. A practical method of estimating an individual's maximal oxygen uptake. Ergonomics 1961;4:97-122.

18 Robertshaw SA, Reed JW, Mortimore IL, Cotes JE. Submaximal alternatives to the Harvard pack index as guides to maximal oxygen uptake (physical fitness). Ergonomics 1984;27:177-85.

19 Yeh MP, Gardner RM, Adams TD, Yanowitz FG, Crapo RO. "Anaerobic threshold": problems of determination and validation. J Appl Physiol 1983;55:1178-86.

20 Cotes JE, Reed JW. Exercise, health and medicine. $\mathrm{Br}$ Med J 1983;286:1895.

21 Cotes JE. The ventilatory cost of activity. Br J Ind Med 1975;32:220-3.

22 Jones NL, Makrides L, Hitchcock C, Chypchar T, McCartney N. Normal standards for an incremental progressive cycle ergometer test. Am Rev Respir Dis 1985;131:700-8.

23 Tanner JM. Fallacy of per-weight and per-surface area standards and their relation to spurious correlation. J Appl Physiol 1949;2:1-15.

24 Lloyd BB, Patrick JM. Respiration and metabolic rate during active and passive exercise in man. $J$ Physiol 1963;165:67P.

25 Cotes JE. Assessment of disablement due to impaired respiratory function. Bulletin de Physiopathologie Respiratoire 1975;11:210-217P. 